\title{
PERENNIAL RYEGRASS INFECTED WITH AR37 ENDOPHYTE REDUCES SURVIVAL OF PORINA LARVAE
}

\author{
J.G. JENSEN and A.J. POPAY \\ AgResearch, Ruakura Research Centre, Private Bag 3123, \\ Hamilton, New Zealand \\ Corresponding author: joanne.jensen@agresearch.co.nz
}

\begin{abstract}
Two pot experiments were conducted to assess the impact of perennial ryegrass (Lolium perenne) infected with AR37, a novel strain of the endophytic fungus Neotyphodium lolii, on porina (Wiseana cervinata) larvae. The wildtype (WT) endophyte, a commercially available novel endophyte strain named AR1, and Nil endophyte ryegrass were also tested. Larval survival was reduced by AR37 in both experiments and by WT in one experiment. Larval weights and head widths, and tiller damage were also reduced by AR37 and, to a lesser extent, by WT. Short-term bioassays with excised tillers showed that $W$. cervinata were slightly deterred from feeding on AR37, but only when offered a choice between AR37 and Nil. No preference was shown between Nil and WT. No effects of AR1 on W. cervinata were observed.
\end{abstract}

Keywords: Wiseana cervinata, Neotyphodium lolii, porina, endophyte.

\section{INTRODUCTION}

Porina, a complex of endemic species of the genus Wiseana (Lepidoptera: Hepialidae), is considered to be a major pest of pastures in New Zealand. Wiseana cervinata is perhaps the most important species of the genus, being the second most widespread (Dugdale 1994) and the most common of the species considered to be damaging to pasture (Perrott 1974; Dugdale 1994).

Control of porina has traditionally been through the use of insecticides applied after pasture damage has appeared, while pasture and stock management techniques have also been investigated (Ferguson 2000). The level of control achieved using these measures is variable, possibly due to differences in response between species (Ferguson 2000). Porina are omnivorous plant feeders, consuming the shoots of both legumes and grasses. Research aimed at identifying alternative pasture species with greater tolerance or resistance to porina has been conducted (e.g. Harris 1969; Harris \& Brock 1972; Farrell et al. 1974), but with the possible exception of phalaris, none are considered likely to be feasible in lowland, intensively farmed areas (Barratt et al. 1990).

In New Zealand perennial ryegrass (Lolium perenne) cultivars containing the naturally occurring endophyte Neotyphodium lolii (wildtype (WT)) protects pastures from pests such as Argentine stem weevil (Prestidge et al. 1982) and black beetle (Ball \& Prestidge 1992). This endophyte produces alkaloids which can be detrimental to livestock (Fletcher et al. 1999), whereas other strains which occur naturally outside of New Zealand produce different combinations of alkaloids and may therefore provide insect resistance without the adverse effects on livestock. The now commercially available strain AR1 produces peramine but not ergovaline or lolitrem B, and has been shown to be effective against Argentine stem weevil (Popay et al. 1999) and to have a degree of resistance to black beetle (Popay \& Baltus 2001). Another experimental strain, AR37, does not produce peramine, lolitrem B or ergovaline but is known to produce a complex of janthitrem alkaloids (Tapper \& Lane 2004). This endophyte affects Argentine stem weevil larvae, but not adults (Popay \& Wyatt 1995). 
Porina are not known to be affected by endophytes in ryegrass, but are sensitive to loline alkaloids produced by N. coenophialum in tall fescue (Festuca arundinacea) (Popay \& Lane 2000). Laboratory studies were conducted to investigate whether the presence of any of three different strains, WT, AR1 and AR37, of the Neotyphodium endophyte provides protection to perennial ryegrass from $W$. cervinata. The effects of the endophytes on survival and growth of $W$. cervinata larvae were assessed in whole plant, pot experiments, and further bioassays were conducted to try to determine the mode of action.

\section{Wiseana cervinata larvae}

\section{METHODS}

For all experiments, W. cervinata larvae were obtained from eggs laid by field-collected adult females. An outside incandescent light situated at Allanton on the Taieri Plain, near Mosgiel, was used to attract adult W. cervinata in November 2002 and 2003. Females were hand collected, placed individually in $60 \mathrm{ml}$ specimen containers and held overnight at room temperature to lay eggs. The moths were subsequently dissected and the bursa copulatrix examined to determine species (Dugdale 1994). Eggs were sent to Ruakura Research Centre where they were surface sterilised with $1 \mathrm{mg} /$ litre copper oxychloride and held at $20^{\circ} \mathrm{C}$ on dampened filter paper in Petri dishes to hatch. On hatching, larvae were transferred to a controlled environment room held at $18^{\circ} \mathrm{C}$, in $60 \mathrm{ml}$ vials containing damp bark chips and were fed a semi-synthetic diet (Popay 2001) until required.

\section{Plants}

Perennial ryegrass (cv. Samson) was used in all experiments. In the first pot experiment ryegrass was either endophyte-free or infected with WT or AR37. In the second pot trial and in the bioassays, ryegrass infected with AR1 was also included. All plants had been grown initially in commercial potting mix in a screenhouse and maintained with regular watering and trimming. Prior to use in each experiment plants were tested for the presence of endophyte using a tissue print immunoassay technique (Hahn et al. 2003).

\section{No-choice pot experiments}

Experiment 1 was set up in February 2003 using 11-week-old larvae. Individual larvae were weighed and their head capsule widths were measured using a graticule in a stereomicroscope at 16x magnification. Each larva was placed into a $15 \mathrm{~cm}$ diameter plastic pot containing an 8-month-old perennial ryegrass plant in a 2:1 soil:sand mix, and with a thin layer of bark on the surface to provide protection for the larvae. There were 20 replicate plants for each endophyte treatment. Larvae were caged on to the plants by sealing drainage holes in the pots with net fabric, and by taping acetate cylinders approximately $14.5 \mathrm{~cm}$ in diameter and open at both ends around the top of the pots. Plants were placed in an $18^{\circ} \mathrm{C}$ controlled environment room with $16: 8 \mathrm{~h}$ light:dark and were bottom-watered as required. The numbers of damaged and undamaged tillers per plant were counted at fortnightly intervals. Damaged tillers were removed at each assessment. Six weeks after larvae were introduced to the pots, they were removed, weighed and head capsule widths measured as described above.

Experiment 2 was set up in January 2004 in the same way as described for Experiment 1 but using 5 -week-old $W$. cervinata larvae and 8 -week-old ryegrass plants. Three larvae were placed on each plant. There were 15 replicates per treatment. Tiller damage was recorded at weekly intervals, with damaged tillers being removed at each assessment. Larvae were removed, weighed and head capsule widths measured after four weeks.

\section{No-choice and choice bioassays}

In March 2004 a no-choice bioassay was conducted using 14-week-old W. cervinata larvae in individual $60 \mathrm{ml}$ plastic vials containing damp bark chips. Each larva was provided with a tiller excised at the stem base from 9-week-old perennial ryegrass plants. There were 20 replicates for each treatment. Each tiller was taken from a different plant and the lengths of the pseudostem and of each leaf blade were measured. The tiller was placed inside a $10 \mathrm{ml}$ plastic test-tube, with the pseudostem protruding slightly from the open end. The test-tube was inverted and the open end held in place over, and just touching, 
the bark in a vial using a circle of felt fabric. The felt was secured over the opening in the vial with a rubber band. Tiller remnants were removed and measured after 3 days.

A choice bioassay using a similar method to the no-choice bioassay was conducted in April 2004. Twenty 17-week-old larvae for each treatment were presented individually with an endophyte free (Nil) tiller plus a tiller infected with WT, AR1 or AR37. The tillers were measured, and held in separate test-tubes pushed through separate holes in circles of felt. Lengths of tiller remnants were measured after 3 days.

\section{Statistical analyses}

Analysis of variance was carried out on larval weight, larval head capsule width and tiller damage data using GenStat Seventh Edition. Data were log transformed where necessary and for these analyses back-transformed data are presented. Larval survival data were analysed by binomial regression.

\section{No-choice pot experiments}

\section{RESULTS}

Larvae feeding on AR37-infected ryegrass had significantly lower survival than those feeding on Nil ryegrass for both no-choice pot experiments $(\mathrm{P}<0.001)$ (Table 1). Final weights and head widths of larvae in the AR37 treatment could not be assessed in experiment 1 , since only one of the 20 larvae survived, but after 4 weeks of feeding on AR37, larvae in experiment 2 were smaller than larvae in the Nil treatment $(\mathrm{P}<0.001)$.

Larval survival was significantly reduced in the WT treatment compared with Nil in experiment $1(\mathrm{P}<0.01)$ but not in experiment $2(\mathrm{P}>0.05)$. Surviving WT larvae had lower body weights than larvae on the Nil treatment in both experiments $(\mathrm{P}<0.05)$. WT larvae also had smaller head widths than those on Nil, although this difference was not statistically significant.

AR1 had no significant impact on survival of larvae relative to Nil or to WT. Weights and head widths of larvae from the AR1 treatment were intermediate between, but not significantly different from, those on Nil and WT (Table 1).

TABLE 1: Survival (\%), final mean weights (mg) and final mean head widths $(\mathrm{mm})$ of $W$. cervinata larvae caged onto ryegrass with different endophyte treatments for 6 weeks in experiment 1 and 4 weeks in experiment 2 .

\begin{tabular}{|c|c|c|c|c|c|c|}
\hline \multirow[b]{2}{*}{ Endophyte } & \multicolumn{2}{|c|}{ Larval survival } & \multicolumn{2}{|c|}{ Final weight } & \multicolumn{2}{|c|}{ Final head width } \\
\hline & Exp. 1 & Exp. 2 & Exp. $1^{1,2}$ & Exp. 2 & Exp. $1^{1,3}$ & Exp. 2 \\
\hline Nil & 95.0 & 55.6 & 447 & 105.1 & 3.72 & 2.32 \\
\hline WT & 55.0 & 51.1 & 321 & 78.9 & 3.52 & 2.17 \\
\hline AR1 & - & 64.4 & - & 95.0 & - & 2.20 \\
\hline AR37 & 5.0 & 13.3 & - & 35.7 & - & 1.81 \\
\hline $\operatorname{LSD}(\mathrm{P}<0.05)^{4}$ & $19.6 * * *$ & $16.8 * * *$ & $98 *$ & $19.0 * * *$ & $0.21 \mathrm{~ns}$ & $0.19 * * *$ \\
\hline
\end{tabular}

${ }^{1} \mathrm{AR} 37$ not included in the statistical analysis as only 1 larva of the 20 survived.

${ }^{2}$ Analysis included initial weight as a covariate.

${ }^{3}$ Analysis included initial head width as a covariate.

${ }^{4} \mathrm{~ns}=$ not significant; $* \mathrm{P}<0.05 ; * * \mathrm{P}<0.01 ; * * * \mathrm{P}<0.001$.

Fewer tillers were damaged by W. cervinata larvae on AR37-infected plants than on Nil plants (experiments $1 \&$ 2) and on AR1 plants (experiment 2) $(\mathrm{P}<0.01)$ (Fig. 1A \& 1B). Tiller damage to WT was intermediate between AR37 and Nil in both experiments, with differences being statistically significant $(\mathrm{P}<0.05)$ from 4 weeks onwards in experiment 1 and at all assessment dates in experiment 2 . In experiment 2 , tiller damage did not differ significantly between AR1 and Nil, and damage to AR1 was higher than to WT from two weeks onwards $(\mathrm{P}<0.05)$ (Fig. 1B). 


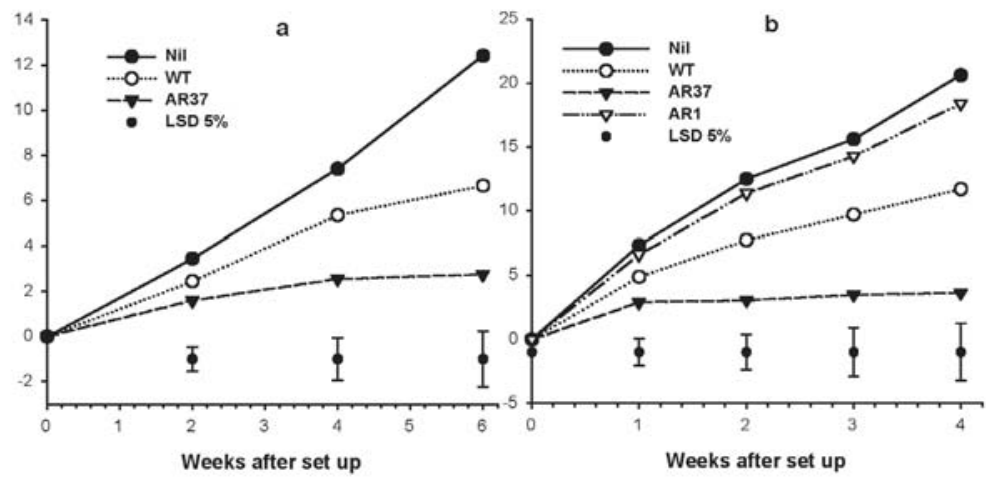

FIGURE 1: Cumulative damage (number of tillers) caused by $W$. cervinata larvae to (a) Nil, WT or AR37 plants over 6 weeks in Experiment 1 or (b) feeding on Nil, WT, AR1 or AR37 plants over 4 weeks in Experiment 2. Error bars are LSD $(\mathbf{P}<0.05)$.

\section{No-choice \& choice bioassays}

In the no-choice bioassay, larvae ate similar amounts of ryegrass from all endophyte treatments (Table 2). However, in the choice bioassay, W. cervinata larvae showed a preference for Nil ryegrass over AR37 $(\mathrm{P}<0.05)$ (Table 3). Larvae did not distinguish between WT and Nil, or between AR1 and Nil, with no significant differences between them in the quantities of leaf and stem (Table 3 ) or leaf + stem (data not shown) consumed $(\mathrm{P}>0.05)$.

TABLE 2: Mean length of stem and leaf $(\mathrm{mm})$ consumed over a 3-day period by 14-week-old $W$. cervinata larvae in a no-choice bioassay.

\begin{tabular}{lrrc}
\hline Endophyte & Stem & Leaf & Total (leaf + stem) \\
\hline Nil & 9.78 & 11.59 & 23.81 \\
WT & 11.13 & 25.03 & 35.52 \\
AR1 & 6.42 & 14.88 & 20.29 \\
AR37 & 5.37 & 9.87 & 15.96 \\
LSD $($ P<0.05) & 8.16 & 24.75 & 37.15 \\
\hline
\end{tabular}

TABLE 3: Mean length of stem and leaf $(\mathrm{mm})$ consumed over a 3-day period by 17-week-old $W$. cervinata larvae in a choice bioassay.

\begin{tabular}{|c|c|c|c|c|c|c|}
\hline & \multicolumn{3}{|c|}{ Stem } & \multicolumn{3}{|c|}{ Leaf $^{1}$} \\
\hline & $\mathrm{E}+{ }^{2}$ & E- & $\mathrm{LSD}^{3}$ & E+ & E- & LSD \\
\hline WT vs Nil & 25.5 & 24.5 & $16.6 \mathrm{~ns}$ & 20.1 & 10.8 & $26.8 \mathrm{~ns}$ \\
\hline AR1 vs Nil & 19.8 & 20.1 & $10.1 \mathrm{~ns}$ & 31.2 & 18.4 & $40.6 \mathrm{~ns}$ \\
\hline AR37 vs Nil & 17.5 & 32.4 & $13.0 *$ & 6.1 & 33.5 & $23.4 *$ \\
\hline
\end{tabular}

${ }^{1}$ analyses carried out on log-transformed data, with backtransformed means and LSD presented.

${ }^{2} \mathrm{E}+=\mathrm{WT}, \mathrm{AR} 1$ or AR37; E- = Nil.

${ }^{3} \mathrm{LSD}$ for $\mathrm{P}<0.05$; ns $=$ not significant, $*=\mathrm{P}<0.05$. 


\section{DISCUSSION}

The negative effects of AR37-infected perennial ryegrass on survival of W. cervinata larvae in the pot trials were shown in the choice bioassay to be at least partially due to feeding deterrence. However, deterrence was not complete since some feeding on AR37 was observed both in pot trials and bioassays, and when offered no choice in the bioassay, consumption did not differ from that in other treatments. It is possible that AR37-infected ryegrass is both deterrent and toxic to $W$. cervinata larvae, although this could not be confirmed due to the short-term nature of the bioassays. Although AR37 has also been shown to reduce damage caused by Argentine stem weevil larvae (Popay \& Wyatt 1995), the mechanisms have not been determined. The role of janthitrems produced by AR37 (Tapper \& Lane 2004) in the insect activity of this endophyte are also as yet unknown.

Wiseana cervinata larvae were not deterred from feeding on perennial ryegrass infected with the WT endophyte, and thus the decreased survival and growth observed in larvae in the two pot experiments appears to be due to toxicity. Of the alkaloids known to be produced by this endophyte, lolitrem B is toxic but not a deterrent to Argentine stem weevil larvae (Prestidge \& Gallagher 1985) while ergovaline is toxic to larvae of the fall armyworm (Spodoptera frugiperda) (Clay \& Cheplick 1989). Peramine has been shown to be highly deterrent to Argentine stem weevil adults (Rowan \& Gaynor 1986), and larvae (Dymock et al. 1988). Peramine had no apparent effect on W. cervinata in these trials since survival and growth of larvae on AR1 did not differ from Nil plants, but further work is needed to confirm this, given that the effects of AR1 were intermediate between Nil and WT and not significantly different from either. Although some protection from $W$. cervinata damage may be achieved by sowing WT-infected ryegrass, the negative effects on livestock make this a less than favourable option. Perennial ryegrass containing AR37 would be more resistant to W. cervinata than WT, but this strain is the subject of ongoing research and is not commercially available.

\section{ACKNOWLEDGEMENTS}

Thanks to Catherine Cameron for statistical analyses, Colin Ferguson for collection and identification of adult W. cervinata, and Wayne Simpson and Anouck de Bonth for developing endophyte immunoassay sheets. This research was funded by the Foundation for Research, Science and Technology (Contract No. C10X0228).

\section{REFERENCES}

Ball, O.J.P.; Prestidge, R.A. 1992: The effect of the endophytic fungus Acremonium lolii on adult black beetle (Heteronychus arator) feeding. Proc. 45th N.Z. Plant Prot. Conf:: 201-204.

Barratt, B.I.P.; van Toor, R.F.; Ferguson, C.M.; Stewart, K.M. 1990: Grass grub and porina in Otago and Southland. A guide to management and control. MAF. 104 p.

Clay, K.; Cheplick, G.P. 1989: Effect of ergot alkaloids from fungal endophyte-infected grasses on fall armyworm (Spodoptera frugiperda). J. Chem. Ecol. 15: 169-182.

Dugdale, J.S. 1994: Fauna of New Zealand No. 30, Hepialidae (Insecta: Lepidoptera). Manaaki Whenua Press. 164 p.

Dymock, J.J.; Rowan, D.D; McGee, I.R. 1988: Effects of endophyte-produced mycotoxins on Argentine stem weevil and the cutworm Graphania mutans. Proc. 5th Australasian Conf. Grassland Invert. Ecol.: 35-43.

Farrell, J.A.K.; Sweney, W.J.; Jones, A.E. 1974: Plant resistance to the porina caterpillar Wiseana cervinata (Lepidoptera: Hepialidae). I. Resistance in legumes and grasses. N.Z. J. Agric. Res. 17: 373-378.

Ferguson, C.M. 2000: Susceptibility of Wiseana species to diflubenzuron and implications for field applications. N.Z. Plant Prot. 53: 430-435.

Fletcher, L.R.; Sutherland, B.L.; Fletcher, C.G. 1999: The impact of endophyte on the health and productivity of sheep grazing ryegrass-based pastures. In: Woodfield, D.R; Matthew, C. ed. Ryegrass endophyte: an essential New Zealand symbiosis. Grassland Research and Practice Series No. 7. Pp. 133-139. 
Hahn, H.; Huth, W.; Schoberlein, W.; Diepenbrock, W. 2003: Detection of endophytic fungi in Festuca spp. by means of tissue print immunoassay. Plant Breeding 122: 217-222.

Harris, W. 1969: Some effects of a porina caterpillar (Wiseana spp.) infestation on perennial ryegrass, cocksfoot, and white clover. N.Z. J. Agric. Res. 12: 543-552.

Harris, W.; Brock, J.L. 1972: Effect of porina caterpillar (Wiseana spp.) infestation on yield and competitive interactions of ryegrass and white clover varieties. N.Z. J. Agric. Res. 15: 723-740.

Perrott, D.C.F. 1974: Porina moth, Wiseana species, life-cycle. DSIR Information Series 105: $1-2$.

Popay, A.J. 2001: A laboratory rearing method for porina. N.Z. Plant Prot. 54: 251.

Popay, A.J.; Baltus, J.G. 2001: Black beetle damage to perennial ryegrass infected with AR1 endophyte. Proc. N.Z. Grassland Assoc. 63: 267-271.

Popay, A.J.; Hume, D.E.; Baltus, J.G.; Latch, G.C.M.; Tapper, B.A.; Lyons, T.B.; Cooper, B.M.; Pennell, C.G.; Eerens, J.P.J.; Marshall, S.L. 1999: Field performance of perennial ryegrass (Lolium perenne) infected with toxin-free fungal endophytes (Neotyphodium spp.). In: Woodfield, D.R; Matthew, C. ed. Ryegrass endophyte: an essential New Zealand symbiosis. Grassland Research and Practice Series No. 7. Pp. 113-122.

Popay, A.J.; Lane, G.A. 2000: The effect of crude extracts containing loline alkaloids on two New Zealand insect pests. In: Paul, V.H.; Dapprich, P.D. ed. 4th International Neotyphodium/Grass Interactions Symposium. Soest, Germany. Pp. 471-475.

Popay, A.J.; Wyatt, R.T. 1995: Resistance to Argentine stem weevil in perennial ryegrass infected with endophytes producing different alkaloids. Proc. $48^{\text {th }}$ N.Z. Plant Prot. Conf:: 229-236.

Prestidge, R.A.; Gallagher, R.T. 1985: Lolitrem B - a stem weevil toxin isolated from Acremonium-infected ryegrass. Proc. $38^{\text {th }}$ N.Z. Weed and Pest Control Conf:: 3840.

Prestidge, R.A.; Pottinger, R.P.; Barker, G.M. 1982: An association of Lolium endophyte with ryegrass resistance to Argentine stem weevil. Proc. 35th N.Z. Weed and Pest Control Conf: : 119-122.

Rowan, D.D.; Gaynor, D.L. 1986: Isolation of feeding deterrents against Argentine stem weevil from ryegrass infected with the endophyte Acremonium loliae. J. Chem. Ecol. 12: 647-658.

Tapper, B.A.; Lane, G.A. 2004: Janthitrems found in a Neotyphodium endophyte of perennial ryegrass. In: Roberts, C.; West, C.P. ed. 5th International Symposium on Neotyphodium/Grass Interactions. In press. 